\title{
SERS Analysis of Self-Assembled Monolayers of DNA Strands on Gold Surfaces
}

\author{
Nak Han Jang \\ Department of Chemistry Education, Kongju National University, Kongju, Chungnam 314-701, Korea \\ E-mail:nhjang@kongju.ac.kr \\ Received November 30, 2009, Accepted December 14, 2009
}

Key Words: SERS, DNA strands, Self-assembled monolayers, Gold surfaces

Surface-enhanced Raman scattering (SERS) is a process in which the Raman scattering intensity of molecules adsorbed on certain rough metal surface, (e.g., $\mathrm{Ag}, \mathrm{Au}, \mathrm{Cu})$ is enhanced by factors of $10^{4}-10^{6}$ compared to the intensity expected for unabsorbed molecules of a comparable concentration. ${ }^{1-3}$ These enormous sensitivity enhancement easily allowed adsorbates of a submonolayer coverage to be readily detected by Raman spectroscopy. The change in the structure of molecules can be followed by observing the changes in the SERS spectra of the adsorbed molecules.

The study of electron transfer through $\mathrm{DNA}^{4}$ and the development of novel DNA detection technologies ${ }^{5}$ have been focused significantly on binding oligonucleosides to metal surfaces and colloids for the variety of important fundamental studies and applications. About ten years ago, Mirkin and coworkers ${ }^{6-8}$ reported a new DNA detection technology based on the sequencespecific interactions of DNA-modified gold nanoparticles probes with a target DNA analyte. Because of these recent advances in using DNA to build a variety of functional materials, ${ }^{9}$ an understanding of how DNA and its building blocks interact with surfaces on the molecular level would be crucial. However, only a few studies have generated pertinent structural information regarding the binding and conformation of oligonucleosides and their building blocks on gold surfaces. ${ }^{10,11}$

Hereby self-assembled monolayers of DNA strands on gold surface have been studied with SERS and data were compared with SERS spectra of oligonucleosides in aqueous gold nanoparticles solution. ${ }^{12}$ Based on this study, the coordination structures of the DNA strands on gold surfaces are proposed.

\section{Experimental}

Approximately $13 \mathrm{~nm}$ diameter gold nanoparticles were prepared by the citrate reduction of $\mathrm{HAuCl}_{4}$ as described previously. ${ }^{12}$ An $0.1 \mathrm{~mL}$ of $4 \%(\mathrm{w} / \mathrm{v}) \mathrm{HAuCl}_{4}$ solution was added to a reflux of $40 \mathrm{~mL}$ of nanopure water while stirring, and then

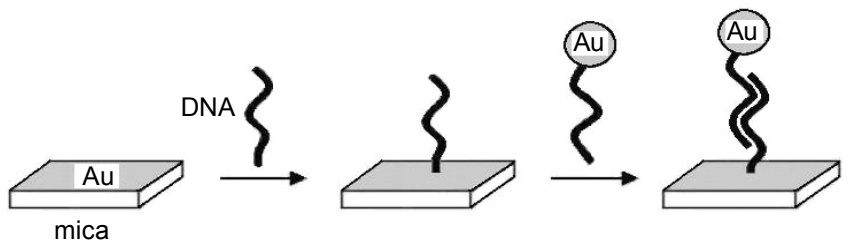

Figure 1. Scheme of preparing for self-assembled monolayers of DNA strands on gold surfaces coated on mica.
$1 \mathrm{~mL}$ of $1 \%(\mathrm{w} / \mathrm{v})$ trisodium citrate solution was quickly added drop by drop while stirring, which resulted in a change of solution color from pale yellow to deep red. After the color change, the resulting mixture was boiled for additional five minutes, allowed to cool to room temperature and the final color of solution obtained was raspberry-red.

Self-assembled monolayers of DNA strands on gold surface were prepared as described previously. ${ }^{13}$ Gold nanoparticles modified with alkylthiol-capped DNA strands were prepared under the presence of specific target DNA strands (Figure 1). A sample spotted with the appropriate 13-nucleotide capture strands was self-assembled on gold surfaces coated on mica with a $0.6 \mathrm{M} \mathrm{NaCl}$ phosphate-buffered saline (PBS) buffer solution (10 $\mathrm{mM}$ of phosphate, $\mathrm{pH} 7)$ in a humidity chamber at room temperature. After 4 hours, the sample was washed four times with $0.6 \mathrm{M} \mathrm{NaCl} \mathrm{PBS}$ buffer solution to remove nonspecifically bound target and was treated with a $0.6 \mathrm{M} \mathrm{NaCl}$ PBS solution of nanoparticle probes $(2 \mathrm{nM})$ for 1.5 hours to effect hybridization with the overhanging region of the target sequence.

SERS spectra were taken as described previously. ${ }^{12}$ SERS spectra of self-assembled monolayers sample were achieved by using a SPEX Model 1877 Triplemate triple grating monochromator at $\lambda_{\mathrm{ex}}=710 \mathrm{~nm}$ and a SPEX Spectrum One charge-coupled device (CCD) detector. The $\mathrm{Ar}^{+}$laser was used to pump a Spectra Physics Tsunami model locked Ti : $\mathrm{Al}_{2} \mathrm{O}_{3}$ laser to obtain $\lambda_{\mathrm{ex}}=710 \mathrm{~nm}$. A band pass filter (Oriel Corporation, Stratford, $\mathrm{CT}$ ) centered at $710 \mathrm{~nm}$ with a $10 \mathrm{~nm}$ range was utilized for removing extra lines.

\section{Results and Discussion}

Good-quality SERS spectrum of DNA single strands was first acquired on gold nanoparticle surfaces (Figure 1) and these tentatively assignments for SERS bands are also listed in Table 1 for comparison the previously measured SERS data ${ }^{12}$ of DNA nucleosides $\mathrm{dA}, \mathrm{dC}, \mathrm{dG}$ and $\mathrm{dT}$ on gold nanoparticle surfaces.

DNA single strands have the order of bases that is 5'-GCTAGA-GTC-GTT-T-3' and contain two characteristic ligating regions which are capable of adsorbing on gold surfaces. They can bind through the heterocylic ring $\mathrm{N}$ atoms and the exocylic functional groups of the purine and pyrimidine bases, and the hydroxy $\mathrm{O}$ atoms of the deoxyribose sugar moiety. In Table 1, SERS bands of DNA single strands showed similarities to SERS bands of bases in DNA nucleosides dA(2'-Deoxyadenosine), $\mathrm{dC}\left(2^{\prime}\right.$-Deoxycytidine $), \mathrm{dG}\left(2^{\prime}\right.$-Deoxyguanosine $)$ and dT(2'-De- 
Table 1. Assignments of SERS spectra of DNA single strands and DNA nucleosides on gold surfaces

\begin{tabular}{|c|c|c|c|c|c|}
\hline \multirow{2}{*}{$\begin{array}{c}\text { DNA } \\
\text { Strands } \\
\text { Single }\end{array}$} & \multicolumn{4}{|c|}{ DNA Nucleosides $^{a}$} & \multirow{2}{*}{$\begin{array}{c}\text { Tentative } \\
\text { Assignment }^{b}\end{array}$} \\
\hline & $\mathrm{dA}$ & $\mathrm{dC}$ & $\mathrm{dG}$ & $\mathrm{dT}$ & \\
\hline 655 & & & 662 & & Ring Breathing $(\operatorname{Im})^{c}$ \\
\hline 800 & & 802 & & 796 & N-C-N Stretching \\
\hline 1014 & 1035 & 1033 & 1032 & 1019 & N-sugar Stretching \\
\hline 1223 & & 1226 & & 1233 & Ring- $\mathrm{CH}_{3}$ Stretching \\
\hline 1295 & & 1293 & & & C-N Stretching \\
\hline 1347 & & & & 1349 & C-N Stretching $(\mathrm{Py})^{c}$ \\
\hline 1378 & 1389 & & & & C-N Stretching(Py) \\
\hline 1452 & & 1458 & & 1450 & $\mathrm{C}=\mathrm{N}$ Stretching $(\mathrm{Py})$ \\
\hline 1595 & 1594 & & & & $\mathrm{NH}_{2}$ Deformation \\
\hline 1642 & & 1639 & 1642 & 1647 & $\mathrm{C}=\mathrm{O}$ Stretching \\
\hline
\end{tabular}

${ }^{a}$ Taken from the previous data in reference [12]. ${ }^{b}$ Assigned from references $[14,15] .{ }^{c}$ Defined imidazole $(\mathrm{Im})$ and pyrimidine (Py).

oxythymidine)

In Figure 2, SERS spectrum of DNA single strands showed the characteristic bands at $800,1014,1295,1347,1452$, and $1642 \mathrm{~cm}^{-1}$. It is concluded that the band at $1014 \mathrm{~cm}^{-1}$ corresponds to the band at $1019 \mathrm{~cm}^{-1}$ of nucleoside dT on gold nanpparticles, which is attributed to the N-sugar stretching mode of thymine. ${ }^{14,15}$ The relatively strong intensity of the band at $1014 \mathrm{~cm}^{-1}$ can be interpreted as a perpendicular standing (edge on) or tilted orientation of the thymine ring in DNA single strands relative to the gold nanoparticle surfaces, whereas as a planner orientation of the thymine ring in dT. This strong enhancement is due to a charge transfer between the aromatic thymine ring and the gold surface. ${ }^{15}$ Another SERS band of DNA single strands is showed band at $800 \mathrm{~cm}^{-1}$, which correspond to bands at 802 $\mathrm{cm}^{-1}$ of dC and $796 \mathrm{~cm}^{-1}$ of dT. This is attributed to the N-C-N stretching mode of the pyrimidine ring.

SERS band of $1295 \mathrm{~cm}^{-1}$ only corresponds to $1293 \mathrm{~cm}^{-1}$ of dC which is attributed to the $\mathrm{C}-\mathrm{N}$ stretching mode of the pyrimidine ring, whereas the band of $1347 \mathrm{~cm}^{-1}$ only corresponds to $1349 \mathrm{~cm}^{-1}$ of dT which is attributed to the C-N stretching mode of the pyrimidine ring. SERS band at $1452 \mathrm{~cm}^{-1}$ of DNA single strands corresponds to bands at $1458 \mathrm{~cm}^{-1}$ of dC and $1450 \mathrm{~cm}^{-1}$ of dT, which are attributed to the $\mathrm{C}=\mathrm{N}$ stretching mode of the pyrimidine ring. SERS band of DNA single strands attributing to $\mathrm{C}=\mathrm{O}$ stretching mode shows at $1642 \mathrm{~cm}^{-1}$, which correspond to bands at $1639 \mathrm{~cm}^{-1}$ of dC, $1642 \mathrm{~cm}^{-1}$ of dG, and $1647 \mathrm{~cm}^{-1}$ of dT.

From analysis of SERS bands up to now, bases of DNA single strands mainly interact through $\mathrm{dC}$ and $\mathrm{dT}$ on gold nanoparticle surfaces. These are also perpendicular standing or tilted orientation relative to the gold nanoparticle surfaces because SERS bands show the relatively strong intensities of the ring stretching modes.

Another SERS spectrum of DNA double strands was showed in Figure 3. These double strands were composed of complementarily matched order of DNA sequence with 5'-GCT-AGAGTC-GTT-T-3' and 3'-CGA-TCT-CAG-CAA-A-5'. SERS spectrum of matched DNA double strands on gold surfaces shows

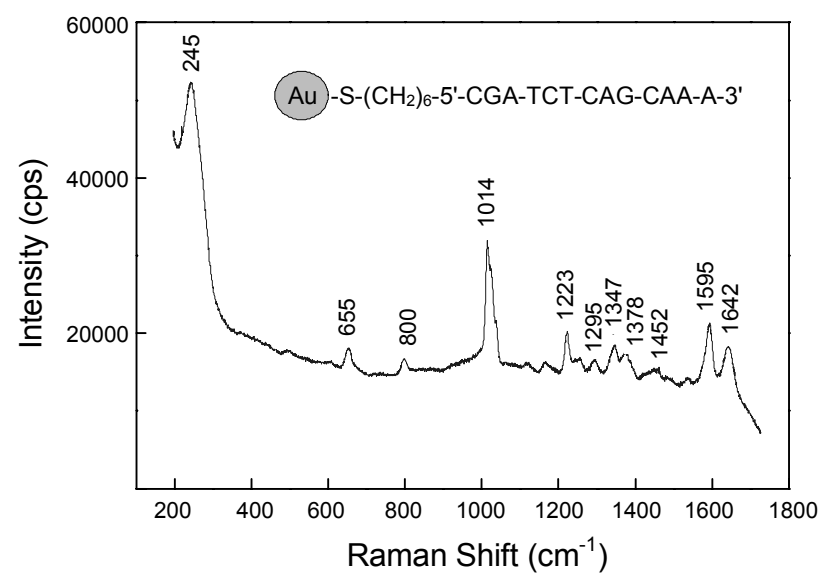

Figure 2. SERS spectrum of DNA single strands on gold nanoparticle surfaces.

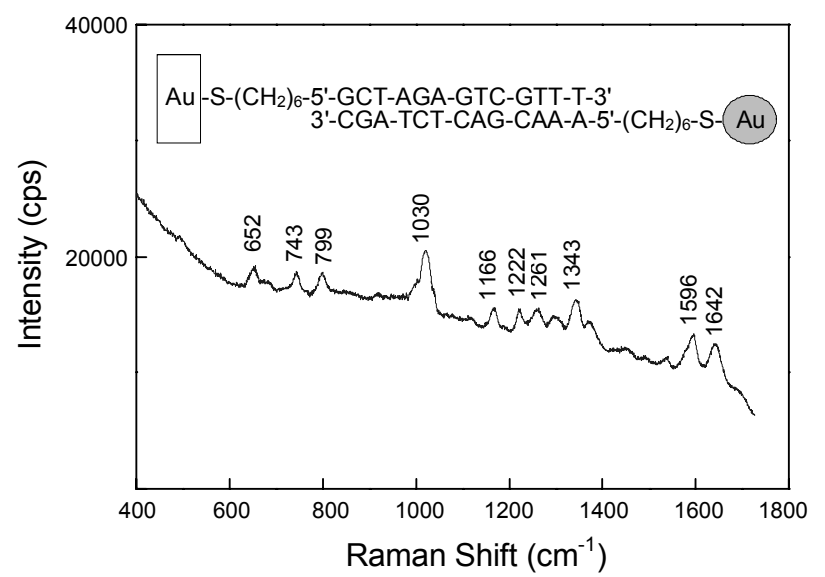

Figure 3. SERS spectrum of DNA double strands(matched) on gold surfaces coated on mica.

similarity to SERS spectrum of DNA single strands on gold nanoparticle surfaces except for the relative intensity of bands. This means that bases of matched DNA double strands dominantly interact through $\mathrm{dC}$ and $\mathrm{dT}$ on gold surfaces like DNA single strands. But relative intensities of SERS band for matched DNA double strands are weak because the low Raman cross section of self-assembled monolayers on gold surfaces. This may be due to no charge transfer between matched DNA double strands and the gold surface because the charge transfer occurs between complementarily matched bases of DNA double strands.

In Figure 4, SERS spectrum of mismatched DNA double strands was showed on gold surfaces. These double strands were composed of mismatched order of DNA sequence with 5'-GCG-CTA-GAG-TCG-TTT-3' and 3'-C-GAT-CTC-AGCAAA-5'. From these DNA sequence, bases of CG doesn't match any other base of complementary order of target DNA sequence. SERS spectrum of mismatched DNA double strands is entirely different from that of matched DNA double strands on gold surfaces. Figure 4 shows the characteristic SERS bands at 735, 790,1322 , and $1470 \mathrm{~cm}^{-1}$. Band at $735 \mathrm{~cm}^{-1}$ corresponds to band at $728 \mathrm{~cm}^{-1}$ of dA, which attributed to ring breathing mode of the pyrimidine, whereas band at $728 \mathrm{~cm}^{-1}$ corresponds to ring 


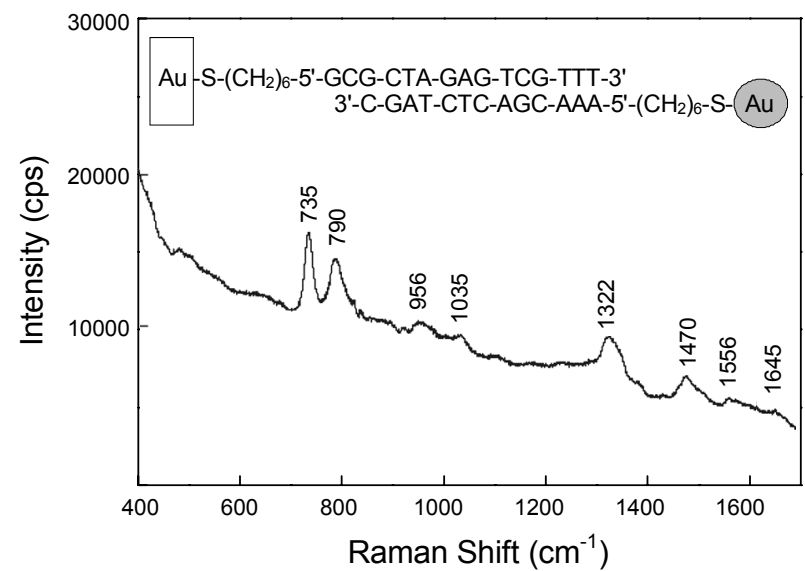

Figure 4. SERS spectrum of DNA double strands(mismatched) on gold surfaces coated on mica.

breathing mode of the imidazole in $\mathrm{dG} .{ }^{12}$ SERS band at 1322 $\mathrm{cm}^{-1}$ also corresponds to band at $1318 \mathrm{~cm}^{-1}$ which represent C-N stretching of the imidazole in dG. Another band at 1470 $\mathrm{cm}^{-1}$ corresponds to band at $1472 \mathrm{~cm}^{-1}$ of dA and is interpreted to $\mathrm{C}=\mathrm{N}$ stretching mode of the pyrimidine.

From analysis of the above data in Figure 4, mismatched DNA double strands mainly interact through $\mathrm{dA}$ and $\mathrm{dG}$ on gold surfaces, contrary to matched DNA double strands. These may also be planner or tilted orientation relative to the gold surfaces because SERS bands of mismatched DNA double strands mainly show ring breathing and stretching modes instead of vibration of amine group. This means that mismatched DNA double strands interact through the nitrogen atom of the pyrimidine ring. Accordingly, this suggests mismatched DNA double strands molecule interact with the gold surface through the nitrogen atom of the pyrimidine ring in $\mathrm{dA}$ and $\mathrm{dT}$. In mismatched DNA double strands, the nitrogen atom seems to play an important role as the side of the molecule with a tendency to interact with gold surfaces.

\section{Conclusions}

DNA strands of self-assembled monolayers were successfully detected using SERS on gold nanoparticle surfaces and gold surfaces coated on mica like other DNA researches. ${ }^{16,17}$ DNA single and matched double strands mainly interact through $\mathrm{dC}$ and $\mathrm{dT}$ on gold surfaces. It showed a perpendicular standing or tilted orientation relative to the gold nanoparticle surfaces whereas a planner orientation on gold surfaces on coated on mica. In contrast, mismatched DNA double strands mainly interact through $\mathrm{dA}$ and $\mathrm{dG}$ on gold surfaces, showing binding through the nitrogen atom of the pyrimidine ring in $\mathrm{dA}$ and dT. DNA strands can interact differently with gold surfaces through matched type between bases of DNA sequence. Accordingly, SERS is very sensitive to detect a small quantity of monolayes or biomaterials on metal surface to elucidate the structure mechanism of them. ${ }^{18,19}$

Acknowledgments. Author thanks Prof. C. A. Mirkin for his considerations at Northwestern University.

\section{References}

1. Metiu, H. In Surface Enhanced Raman Scattering; Chang, R. K., Furtak, T. E., Eds.; Plenum: New York, 1982; pp 1-34.

2. Fleischmann, M.; Hendra, P. J.; McQuillan, A. Chem. Phys. Lett. 1974, 26, 163-166.

3. Jeanmarie, D. L.; Van Duyne, R. P. J. Electroanal. Chem. 1977, $84,1-20$

4. Mucic, R. C.; Herrlein, M. K.; Mirkin, C. A.; Letsinger, R. L. Chem. Commun. 1996, 555-557.

5. Thiel, A. J.; Frutos, A. G.; Jordan, C. E.; Corn, R. M.; Smih, L. M. Aanal. Chem. 1997, 69, 4948-4956.

6. Mirkin, C. A.; Letsinger, R. L.; Mucic, R. L.; Storhoff, J. J. Nature 1996, 382, 607-609.

7. Elghanian, R.; Storhoff, J. J.; Mucic, R. L.; Letsinger, R. L.; Mirkin, C. A. Science 1997, 277, 1078-1081.

8. Storhoff, J. J.; Elghanian, R.; Mucic, R. L.; Mirkin, C. A.; Letsinger, R. L. J. Am. Chem. Soc. 1998, 120, 1959-1964.

9. Alivisatos, A. P.; Johnsson, K. P.; Peng, X.; Wilson, T. E.; Loweth, C. J.; Bruchez, Jr., M. P.; Schultz, P. G. Nature 1996, 382, 609-611.

10. Hegner, M.; Wagner, P.; Semenza, G. FEBS Lett. 1993, 336, $452-$ 456.

11. Zimmermann, R. M.; Cox, E. C. Nucleic Acids Res. 1994, 22, $492-$ 497.

12. Jang, N. H. Bull. Korean Chem. Soc. 2002, 23, 1790-1800.

13. Cao, Y. W.; Jin, C. R.; Mirkin, C. A. Science 2002, 297, 1536-1540.

14. Varsanyi, G. Assignments for Vibrational Spectra of Seven Hundred Benzene Derivatives; John Wiley \& Sons: New York, 1974; Vol. 1.

15. Lin-Vien, D.; Colthup, N. B.; Fateley, W. G.; Grasselli, J. G. The Handbook of Infrared and Raman Characteristic Frequencies of Organic Molecules; Academic Press: Boston, 1995.

16. Lee, C. J.; Kang, J. S.; Kim, M. S.; Lee, K. P.; Lee, M. S. Bull. Korean Chem. Soc. 2004, 25, 1211-1216.

17. Bell, S. E. J.; Sirimuthu, N. M. S. J. Am. Chem. Soc. 2006, 128, 15580-115581.

18. Joo, S. W. Bull. Korean Chem. Soc. 2008, 29, 1761-1764.

19. Kim, J. E.; Kim, H. J.; Yoon, S. Bull. Korean Chem. Soc. 2009, 30, 999-1000. 